\title{
Formación de valores a través de textos escolares en la Guerra del Pacífico
}

Cecilia ISRAEL LA ROSA / Instituto de Estudios Peruanos

\section{Resumen}

Este artículo es parte de una ponencia que se presentó en el IV Encuentro Peruano-Chileno de Historiadores, en Santiago de Chile en Octubre de 1997, y es producto de un taller de investigación que se dictó a un grupo de alumnos de la Universidad del Pacífico. No con poca sorpresa vemos que todavía tiene actualidad y es relevante para los estudiosos del área de educación y de los textos escolares. Trata de ser un análisis de los textos escolares peruanos de Historia en los capítulos que tienen que ver con el conflicto bélico entre ChilePerú (1879-1881), de los cuales resaltamos los calificativos que se utilizan cuando se hace referencia a los chilenos, empezando a proponer alternativas que pongan de lado la adjetivación sin dejar de presentar la verdad de los hechos.

\section{Palabras clave:}

Historia, educación, textos escolares, integración.

\section{Abstract}

This article presents a part of a lecture presented in the IVth Congress of Peruvian-Chilean Historians in Santiago of Chile on October 1997, and is a product of a Research Workshop held for a group of students at the Universidad del Pacifico. Surprisingly enough we realize that it is still relevant for researchers in the area of education and of school texts. It is mainly an analysis of Peruvian history school text books, in the chapters that have to do with the war that took place between Peru and Chile (18791881 ), where the adjectives used in our texts when reference is made to the Chileans, have been brought out. Some alternatives are proposed to do away with adjectives while still presenting the truth of the facts. 


\section{Key words:}

History, education, school texts, integration.

Los textos escolares en el área de estudios sobre la Historia del Perú permiten interpretar hechos históricos y la realidad de la que forma parte el estudiante. De este modo podrá insertarse concientemente en su sociedad, con el compromiso de trabajar por la paz, la solidaridad, la justicia y la defensa de los Derechos Humanos. La memoria histórica es fundamental para entender e identificarnos con nuestro pasado y proyectarnos al futuro.

Presentaremos lo que dicen los dos textos escolares más vendidos en el Perú', el de Juan Castillo Morales (veinticinco años como autor de textos escolares) y el de Gustavo Pons Muzzo (con más de doce ediciones) en sus capítulos sobre la Guerra con Chile. Son textos para jóvenes de 15 a 17 años de edad. Esta línea de investigación, de los textos escolares, fue motivada por un ambiente antichileno que se estaba dando en algunos sectores de nuestra sociedad frente a las inversiones $y / 0$ empresarios chilenos en el año 1997 y que ha continuado hasta hoy en día con sus altas y bajas.

\section{Integración}

La integración tiene muchas facetas, pero creo que para que estos esfuerzos no se queden solamente a nivel declarativo, un buen aporte podría ser mejorar los textos escolares, tanto los nuestros como los de nuestros vecinos del sur, ya que éstos son importantes medios de transmisión de conocimientos y valores. A pesar de que: "...el libro de texto forma parte de las actividades cotidianas permanentes, sin embargo, su uso parece no estar incorporado de forma sistemática en ellas." La presentación de estos calificativos en los textos, me gustaría que nos lleven a preguntarnos si así podemos hacer integración. Me gustaría decir que hay que tomar por asalto los textos escolares; o como dice nuestra prestigiosa historiadora

\footnotetext{
${ }^{1}$ Dato que corresponde a 1997, que viene de años anteriores y continúa hasta el año 2005 (cuando el Ministerio de Educación empieza a repartir el texto Enfoques 4/Ciencias Sociales, Editorial Norma S.A.C. a los alumnos de Cuarto de Secundaria. Sin embargo, los textos anteriores siguen siendo un referente importante para los profesores de Ciencias Sociales en las escuelas. Es decir, son usados como material de consulta para la elaboración de sus clases y han sido parte de la formación de varias generaciones de alumnos y profesores. Uno de los libros que reparte hoy el MED es Ciencias Sociales 4 Secundaria, Editorial Santillana S.A. Lima, Febrero 2008; este último ha dejado de lado muchos de los adjetivos al referirse a los chilenos dentro del tema de la guerra de 1879-1881. Pero "...debido a la limitada capacitación que reciben los maestros en materia de textos escolares y al escaso tiempo que dedican a reflexionar sobre las posibilidades de estos últimos, el aprovechamiento de dichos materiales en las aulas de las escuelas estatales del Perú se ve seriamente limitado". En: Eguren, Mariana; Carolina de Belaunde y Natalia González. Recursos desarticulados - El uso de textos en la escuela pública. Lima, Instituto de Estudios Peruanos, 2005, p. 96.
}

${ }^{2}$ Op Cit, p. 12. 
María Rostworoski, los textos escolares son para el tacho de basura. "La falta de capacitación a los maestros sobre las posibilidades de uso del texto escolar y su relación con la estructura curricular constituyen un serio obstáculo para que el esfuerzo por dotar a todas las escuelas peruanas de libros tenga un impacto positivo en los alumnos." 3

Recordemos algunos hitos en nuestra historia, empezando por Simón Bolívar, que es reconocido como el abanderado de la Patria Grande y como visionario de la Integración Americana. Bolívar pertenece a su tiempo y la gesta que él protagoniza es la gesta de los criollos que se rebelan contra la monarquía española.

En su Discurso de Angostura (Colombia) ante el Congreso en 1819 declaró: "Al desprenderse la América de la Monarquía Española... nosotros (los americanos)... no somos europeos, no somos indios, sino una especie media entre los aborígenes y los españoles... la América todo lo recibía de España... no permitiéndonos sus funciones en nuestros asuntos domésticos y administración interior. Esta abnegación nos había puesto en la imposibilidad de conocer el curso de los negocios públicos; tampoco gozábamos de la consideración personal que inspira el brillo del poder a los ojos de la multitud, y que es de tanta importancia en las grandes revoluciones... estábamos abstraídos, ausentes del universo en cuanto... a la ciencia del Gobierno... Nuestros débiles conciudadanos tendrán que robustecer su espíritu mucho antes que logren digerir... la libertad... Sólo la democracia, en mi concepto, es susceptible de una absoluta libertad; pero ¿cuál es el gobierno democrático que ha reunido a un tiempo, poder, prosperidad y permanencia?... Tengamos presente que nuestro pueblo no es el europeo, ni el americano del Norte, que más bien es un compuesto de África y de América, que una emanación de Europa... Es imposible asignar con propiedad a qué familia humana pertenecemos. La mayor parte del indígena se ha aniquilado, el europeo se ha mezclado con el americano y el africano, y éste se ha mezclado con el indio y con el europeo. Nacidos todos del seno de una misma madre, nuestros padres, diferentes en origen y en sangre, son extranjeros y todos difieren visiblemente en la epidermis; esta desemejanza trae un reto de la mayor trascendencia... Necesitamos de la igualdad para refundir en un todo, la especie de los hombres, las opiniones políticas y las costumbres públicas... La reunión de la Nueva Granada y Venezuela en un gran Estado ha sido el voto uniforme de los pueblos y gobiernos de estas Repúblicas. La suerte de la guerra ha verificado este enlace tan anhelado por todos los Hispanoamericanos; de hecho estamos incorporados." 4

${ }^{3}$ Op cit, p. 93-94.

${ }^{4}$ Bolívar, Simón. El Discurso de Angostura ante el Congreso el 15 de febrero de 1819. En: Bolívar, Simón. Doctrina del Libertador. Caracas, Biblioteca Ayacucho, 1979, pp. 101-127. 
En una carta del Libertador al General Santander en enero de 1825 leemos: "Veo la guerra civil y los desórdenes volar por todas partes, de un país a otro, mis dioses patrios devorados por el incendio doméstico... vuelvo, pues, a mi primer proyecto como único remedio: la federación (Confederación entre Estados). Esta federación me parece a mí un templo de asilo contra las persecuciones del crimen. Por lo mismo, estoy determinado a mandar los diputados del Perú al Istmo inmediatamente que sepa que Colombia quiere mandar los suyos a dar principio a la unión. No dudo que México y Guatemala harán lo mismo, y aún Buenos Aires y Chile después... Yo insto a Ud., mi querido general, para que se apresure en dar este inmenso paso. Solamente esta expectativa me retendrá en América algún tiempo, hasta que se realice el congreso americano... El mes que viene se reunirá el Congreso del Perú. Dicen estos señores que no quieren que me vaya, ni que renuncie a mi mando, mas yo lo haré a su pesar... El único objeto que me retiene en América, y muy particularmente en el Perú, es el dicho congreso... porque estoy bien persuadido que sin esta federación no hay nada." ${ }^{5}$

Bolívar le escribe al General Sucre en febrero de 1825: "Ni Ud., ni yo, ni el congreso mismo del Perú, ni de Colombia, podemos romper y violar la base del derecho público que tenemos reconocido en América. Esta base es que los gobiernos republicanos se fundan entre los límites de los antiguos virreinatos, capitanías generales, o presidencias como la de Chile. El Alto Perú es una dependencia del virreinato de Buenos Aires: dependencia inmediata como la de Quito de Santafé. Chile, aunque era dependencia del Perú, ya estaba separado del Perú algunos años antes de la revolución, como Guatemala de Nueva España. Así es que ambas... presidencias han podido ser independientes de sus antiguos virreinatos; pero Quito ni Charcas pueden serlo en justicia, a menos que, por un convenio entre partes, por resultado de una guerra o de un congreso, se logre entablar y concluir un tratado." 6

Sobre Bolívar, nuestro agudo historiador del Perú, Pablo Macera, comenta que sus propósitos chocaron contra los criollos y contra el país, donde no existía integración nacional. "El Perú fue durante largos años el centro de reacción militarista colonial española para todos los criollos suramericanos. Fue la hora del fidelismo, aparente causa del resentimiento neogranadino, bonaerense y chileno contra el Perú. Por aquellos años vencer al Perú era vencer a España. De aquella hora arrancan muchos de los malentendidos

\footnotetext{
${ }^{5}$ Carta del Libertador al General Santander del 6 de enero de 1825. En: Bolívar... Doctrina... pp. 181, 186.

${ }^{6}$ El Libertador escribe al General Sucre el 21 de febrero de 1825 sobre el principio por el cual las nuevas Naciones Hispanoamericanas debían constituirse en los límites de las grandes divisiones del Imperio español en América. En: loc.cit, pp. 188-190.
} 
que confundieron tanto las relaciones entre los criollos peruanos y los libertadores extranjeros."

"Bolívar pareció ignorar el peso de tantos milenios de historia peruana y creyó poder gobernar un Estado multinacional en donde habían fracasado chapines, waris, incas y españoles, sin comprender que el país aglutina un conjunto de nacionalidades, un mosaico de pueblos a los que es necesario primero integrar dentro de una conciencia estatal multivalente para conformar un Estado en el que se correspondan predeterminaciones históricas de quechuas, aymaras, huancas, huaylas, andinos o trasandinos, amazónicos o costeños. Es decir una república de indios y mestizos, en donde pueda restituirse la solidaridad quebrada... La impaciencia y genialidad de Bolívar no pudieron cambiar estas predeterminaciones históricas; la misma dureza dictatorial que empleó contra el Perú demostraba cuán débiles resultaban en este país sus recursos políticos: donde habían gobernado durante dos mil años chapines, waris, incas y españoles, había una infinita capacidad de adaptación y disimulos que ponían en jaque a todas las utopías. Bolívar no pudo imponer a los hombres del Perú una solidaridad americana. Los criollos prefirieron pensar en pequeño."

Desde la Confederación Perú-Boliviana del año 1836-1839 se suceden guerras en el mundo latinoamericano, se demarcan fronteras y se atizan enemistades. Recién en 1960, por necesidades de mercado, empiezan a surgir proyectos de intención integracionista, se fundó la ALALC (Asociación Latinoamericana de Libre Comercio) y el MCCA (Mercado Común Centroamericano); en 1969, se crea la CAN (Comunidad Andina de Naciones).

El Convenio Andrés Bello de 1970 pretende la integración educativa, científica y cultural, para así preservar la identidad cultural "latinoamericana" y con este trabajo lograr que todas estas naciones se desarrollen más y eleven los niveles de vida de los pueblos. Se impone tareas para el conocimiento mutuo, buscando instituciones que hagan intercambio cultural, logrando que las bibliotecas tengan secciones de otros países, y fomentando cursos de historia y geografía de los demás países. Para armonizar sistemas educativos hay que reconocer en cada país los estudios primarios y secundarios, recopilar y procesar información estadística uniforme en cada país para alcanzar niveles de comparabilidad. Para lograr esto, resulta inevitable realizar estudios sobre diversos aspectos de la educación, la ciencia y la cultura para tener objetivos comunes en los sistemas educativos y poder así producir textos escolares comunes. Pero el funcionamiento de este convenio depende principalmente de la voluntad

\footnotetext{
${ }^{7}$ Macera, Pablo. Visión Histórica del Perú. Lima, Editorial Milla Batres, 1978.

${ }^{8}$ Loc.cit.
} 
política de los ministros de Educación de los diferentes países ya que ellos formulan y ejecutan el Convenio, sufriendo éste los avatares políticos del caso, sin dejar de ser un buen intento y loable declaración.

En 1983 otro intento integracionista, la Corporación Integral para el Desarrollo Cultural y Social, CODECAL, con la UNESCO, inició un trabajo de consulta sobre la enseñanza de la historia en Colombia, Ecuador, Perú y Venezuela. Una historia comprendida no como la sucesión de agudas confrontaciones entre naciones, sino como el entramado de relaciones estructurales, dinámicas y potenciadoras del escenario para la cooperación, la solidaridad y la integración.

En 1986 se forma el Grupo de Río, el MERCOSUR (Mercado Común del Sur) en 1991, y la UNASUR (Unión de Naciones Sudamericanas) en 2004, principalmente con fines comerciales; sin embargo, cada uno trabaja por su lado en vez de integrarse. El MERCOSUR parece que es el que tiene mayores posibilidades de avanzar en una integración más profunda.

En 1992 el Convenio Andrés Bello patrocinó un análisis de los programas y textos de enseñanza de la historia de los países que trabajó CODECAL agregando a Bolivia. En el acta se invoca a: "Instruir a los ministros de Educación a constituir un grupo de trabajo para que proceda a armonizar los textos de enseñanza de la historia, haciéndolos compatibles con los propósitos de la integración andina y latinoamericana." 9

La historia debe ayudarnos a construir espacios a favor de la paz, la solidaridad y el respeto recíproco entre grupos humanos; debe ayudarnos a eliminar las diferencias que nos separan para fortalecer la identidad colectiva, a fin de construir una sociedad sin fronteras.

El trabajo de CODECAL propone que el sentido de "patria" debe ser ampliado al de "nación", de modo que pueblos diferentes nos sintamos unidos y trabajemos juntos por un futuro común. "El patrioterismo nacionalista, cerrado a los vecinos, no ha hecho sino retardar el avance que América Latina bien se merece, y ofrece nuestra debilidad inerme para beneficio de otros. Habiendo recorrido un camino sistemático de desintegración especialmente a partir de la Independencia, es tiempo de retomar en alguna forma el sueño bolivariano. Los conflictos entre nuestros países no deberán seguir resolviéndose por demagogia nacionalista exacerbada por los medios de comunicación ni con el argumento del número de soldados o de aviones de guerra, sino con una actitud de equidad que se traduzca en respeto y colaboración a través de la negociación y el consenso entre

${ }^{9}$ Díaz Castañeda, Jaime y Jaime Ospina Ortiz. La Enseñanza de la Historia como Estrategia de Integración, Bogotá, SECAP. 
iguales." ${ }^{10} \mathrm{El}$ trabajo de CODECAL corresponde sólo a cuatro países andinos, para un período de la educación primaria y un tema: Ia Independencia.

\section{Calificativos usados en los textos escolares: antes, durante y después de la Guerra entre Chile y Perú}

2.1. Los siguientes apuntes son del texto escolar de Historia del Perú de Juan Castillo Morales para cuarto de secundaria, alumnos de quince o diecisiete años de edad. Este libro de historia ha sido el más vendido en el país durante varios años."

\subsubsection{Situación del Perú antes de la Guerra:}

"El infausto episodio de la guerra con Chile... quebrantó el incipiente transcurrir de nuestra vida republicana." "...la ineficacia de la diplomacia peruana para utilizar el único terreno en el que podía haber neutralizado el desorbitado afán del expansionismo chileno..."

\subsubsection{Causas de la Guerra:}

"Las riquezas guaneras y salitreras detectadas en el sur peruano y el litoral boliviano despertaron el ansia de los capitalistas chilenos..."

"El afán expansionista chileno para compensar la pobreza de recursos de su territorio."

"Hoy es una verdad histórica, comprobada con documentos oficiales de Chile y por sus mismos publicistas, que la verdadera causa de la guerra declarada por esta nación al Perú y Bolivia en 1879, era la ambición de ensanchar su territorio a costa de éstos; los guanos de la costa y las salitreras de Atacama y Tarapacá embargaban la codicia del gobierno y del pueblo chileno." (Cita de Mariano Felipe Paz Soldán).

\subsubsection{La Misión Diplomática de Lavalle:}

"El pueblo chileno lo recibió hostilmente, efectuando actos de violencia contra nuestro consulado".

\subsubsection{Combate Naval de Iquique:}

Acciones del Huáscar contra la Esmeralda "...salvando, luego, a los tripulantes enemigos en un acto de suma generosidad."

\footnotetext{
${ }^{10}$ Loc. cit.

${ }^{11}$ Castillo Morales, Juan. Historia del Perú en el Proceso Americano y Mundial, Lima, Editorial Bruño.
} 
Acciones de la Covadonga contra el Independencia "...hundiéndose y siendo ametrallados sus tripulantes por la marinería chilena."

\subsubsection{Combate de Angamos:}

"...Grau supo poner la nota de humanidad y respeto a las leyes de los pueblos civilizados." Menciona el reconocimiento de las hazañas de Grau el historiador chileno Vicuña Mackenna.

"No obstante, este pueblo, recogiéndose dentro de sí mismo, y comprimiendo su hondo dolor, en vez de entregarse a los furores de la desesperación y de ofrecer un triste espectáculo de su desbordamiento, como tan frecuentemente sucedía en Chile, sobrellevó su desgracia con aquella estoica resignación propia de los espíritus superiores." (Cita a Mariano F. Paz Soldán).

\subsubsection{Batalla de Arica:}

"...se hizo sentir, nuevamente, el fuego de la artillería enemiga sobre los heroicos defensores que se aprestaban para la resistencia... los chilenos cambiaron de posición, engañando a los defensores de Arica... Abrumadora superioridad numérica ${ }^{12}$ equiparada, únicamente, con el valor y el sacrificio de quienes allí se inmolaron. Casi todos nuestros oficiales cayeron en la acción... y el mismo Bolognesi, que murió atravesado por una bala de rifle y después le destrozaron el cráneo... La matanza efectuada por chilenos fue tremenda; hoy no hay prisioneros, fue la consigna, pocos fueron los que se salvaron ya que el enemigo puso en práctica el bárbaro y salvaje sistema del repase."

"Concluido el combate y consumado el degüello de los prisioneros, los vencedores descendieron del Morro, y unidos con el resto del ejército, que ya se encontraba en la población, emprendieron la obra devastadora, empezaron por las bodegas y tiendas de licores y víveres y embriagados con el alcohol mezclado con la sangre, continuaron el saqueo de casas en donde no se respetó el pudor ni de las ancianas... cuanto hombre encontraban, fuera o no soldado, caía bajo el filo del alevoso corvo... El Perú se encontraba solo y desamparado, completamente solo." (Cita a Paz Soldán).

\subsubsection{Campaña sobre Lima:}

Primeras negociaciones de paz.- Intervención de los Estados Unidos como mediador. "Debido a la intransigencia del invasor... las negociaciones fracasaron."

\footnotetext{
${ }^{12}$ El historiador chileno Gonzalo Bulnes en Guerra del Pacífico (1912) afirma lo contrario: "Perú tenía un ejército de cuatro a cinco mil hombres...Chile tenía en esa época un pequeño ejército de 2,440 plazas."
} 
La expedición Lynch.- "...para que la guerra sea humana, es necesario que sea tremenda y terrible; la guerra humanitaria no hace más que embarazar las operaciones y hacer perder el tiempo... La expedición Lynch ha sido pues una operación bien llevada, que nos ha enseñado cómo debemos hacer la guerra", palabras de un senador chileno "ensoberbecido por la victoria."

Líneas defensivas de Lima.- "La prensa y la opinión popular chilena exigían ocupar Lima."

Batalla de San Juan.- "Los chilenos entraron en la Villa de Chorrillos, donde se dedicaron, como lo habían venido haciendo en ciudades capturadas del sur, al saqueo, al asesinato inmisericorde y, sobre todo, a la embriaguez."13

Batalla de Miraflores.- "...los chilenos, como tenían a su gente embriagada, a la vez que cansada, fingieron entrar en negociaciones, cuando en realidad lo hacían para ganar tiempo y reponerse."

Ocupación de Lima.- "...nombraron como gobernador de la ciudad al bárbaro y salvaje Patricio Lynch."

\subsubsection{La Resistencia de la Sierra:}

Cambios Políticos en el Perú.- "...para que llevase adelante las gestiones de paz, fue nombrado... don Francisco García Calderón como Presidente de la Nación. Este jurisconsulto llevó a cabo diversas gestiones con la condición de que la paz se estableciera sin desmembración territorial para nuestro país... los chilenos lo apresaron y lo embarcaron rumbo a Chile, donde fue objeto de numerosas vejaciones y actos de hostilidad cometidos contra su persona."

La Campaña de la Breña.- "...los chilenos habían ocupado ya toda la costa sur y arrasado con las haciendas cañaveleras del norte, sin embargo, no habían podido hacer lo mismo con la sierra central, donde actuaba el general Cáceres."

Batalla de Huamachuco.- "Cayó herido el joven oficial Leoncio Prado, hijo del ex presidente Ignacio Prado y fue fusilado."

\subsubsection{Tratado de Paz de Ancón:}

"Después de la firma del Tratado, el general Lynch y sus 4000 hombres se instalaron en Chorrillos, llevándose consigo todo cuanto estuvo a su alcance. Se necesitaron más de 3000 carretas para transportar todo el

\footnotetext{
${ }^{13}$ En cambio en HOY, Semanario Chileno, "100 Años Después - La Guerra del Pacifico", mayo de 1979, podemos leer en la leyenda de la reproducción de un grabado: "Entrada a Lima: ordenada llegada chilena contrastó con saqueos protagonizados por los propios peruanos." P. 40.
} 
botín, no quedó nada en la Casa de Gobierno, ni en ninguno de los otros edificios públicos, excepto las habitaciones con sus cuatro paredes."14

\subsubsection{Consecuencias de la Guerra:}

"Nunca ningún pueblo civilizado sufrió y pagó tanto por la codicia, sin límites, del invasor. Pérdida de territorios y de la venta del guano mientras duró la ocupación; descenso de la producción agrícola y minera; destrucción de las haciendas costeñas, de los ingenios azucareros, de innumerables objetos de arte y de obras públicas; desaparición de la escuadra marítima y de muchos jóvenes, caudillos militares e intelectuales que constituían la esperanza de la nación; aparición de límites con el invasor por el lado sur."

"Estas son las consecuencias más saltantes de la guerra con Chile, cuyo botín está calculado en dos mil trescientos cincuenta millones de pesos, que incrementaron las anémicas arcas fiscales del lánguido país del sur y que desangraron a nuestra Patria hasta en lo más íntimo de sus entrañas."

"Por eso, la juventud de hoy, al tomar conciencia de los hechos que acarreó la guerra infausta, que si bien nos quitó tierras, nos legó héroes ejemplificares, debe estar alerta en su espíritu y preparada en su acción, para que acontecimientos de esta naturaleza: ¡Nunca más se vuelvan a repetir!”

\subsubsection{Situación del Perú después de la Guerra:}

“...hacia 1919, nos da ya la imagen de un Perú que ha logrado sacudirse del impacto y de la crisis que generara la Guerra del Pacífico, aún cuando esté pendiente el problema de Tacna y Arica y el no haber olvidado -como creemos que no se olvidará- la amarga experiencia de esta derrota."

\section{Observaciones al texto:}

- La narración está diseñada para que sea leída únicamente por personas de nacionalidad peruana. El mundo se reduce al escenario nacional.

- Versiones de historiadores peruanos y algunos chilenos, siempre destacando valores por el lado peruano (caballerosidad).

- Una visión de la historia de este momento limitada a los acontecimientos entre Perú, Bolivia y Chile. Sin mencionar el rol que jugaron los habitantes de la zona fronteriza de estos tres países y del papel que desempeñaron los ingleses. Para ilustrar esto: en Tarapacá trabajaban

\footnotetext{
${ }^{14}$ HOY Semanario chileno... Lynch "luego de Chorrillos y Miraflores, se convirtió en jefe político y militar del Perú hasta 1884. Poner orden en una ciudad abandonada, sin disciplina, autoridades ni recursos, fue una labor que Lynch llevó a cabo en forma admirable."
} 
y vivían juntos en campamentos ciudadanos bolivianos, peruanos y chilenos.

- Hay una tendencia a relacionar salvajismo, barbarie, superioridad, poderío con Chile y sacrificio, entrega, orgullo, pundonor, inferioridad con el Perú.

- Ciertos pasajes de combates o batallas son narradas épicamente, como una novela.

Hay ausencia de la situación económica, social y política en el Perú. Por ejemplo, del capítulo analizado hay una página al principio dedicada a este problema, treinta al conflicto y un párrafo final que vuelve a mencionar lo catastrófica que estaba la situación económico-política en el Perú.

En conclusión, el relato épico puede ser aplicado a cualquier guerra, Bosnia, Argelia, Malvinas, etc., sólo habría que cambiar fechas y nombres de héroes.

2.2. Los siguientes extractos son del texto escolar de Historia del Perú de Gustavo Pons Muzzo, utilizado en tercero, cuarto o quinto de secundaria, alumnos de catorce a diecisiete años de edad. Este fue el segundo texto mas vendido durante varios años. ${ }^{15}$

\subsubsection{Combate Naval de Iquique:}

"...los chilenos de la Covadonga se aprovecharon y ametrallaron bárbaramente a los náufragos del Independencia, mientras que en Iquique, Grau salvaba a los náufragos de la Esmeralda."

\subsubsection{Combate de Angamos:}

"...los disparos de los chilenos no estaban destinados a hundir el buque, sino a matar a su comandante."

\subsubsection{Campaña de Tarapacá:}

"...Tarapacá estaba perdido, lo que tuvo graves consecuencias, porque los chilenos inmediatamente comenzaron a explotar el salitre, obteniendo el apoyo de Inglaterra, interesada en esa riqueza."

\subsubsection{Batalla de Arica:}

"...cerca de 7000 chilenos al mando del Coronel Pedro Lagos se lanzaron al ataque con la consigna: no hay prisioneros."

\footnotetext{
${ }^{15}$ Pons Muzzo, Gustavo. Compendio de Historia del Perú, Lima, Editorial Bruño, duodécima edición, 1995.
} 


\subsubsection{Expedición de Lynch a la Costa Norte del Perú:}

"La obra de destrucción se llevó a cabo sistemáticamente y bárbaramente. La dinamita fue el agente que se empleó para destruir los muelles y todos los edificios públicos."

\subsubsection{Campaña de Lima:}

"En la noche, los chilenos eran dueños de Chorrillos, y la soldadesca, influenciada por sus jefes, se dedicó al saqueo e incendio de las lujosas residencias..."16

\subsubsection{Batalla de Miraflores:}

“...los chilenos solicitaron de Piérola pactar un armisticio para hacer la paz, pero en realidad lo hacían para ganar tiempo, pues sus soldados se encontraban desbandados y borrachos..."

\subsubsection{Guerra de la Resistencia en la Sierra:}

"En Huamachuco también se puso en práctica la consigna 'no hay prisioneros' y quien no cayó en el campo de batalla fue fusilado en donde se le encontraba... fue fusilado el Coronel Leoncio Prado, quien fue herido en la batalla y luego tomado prisionero."

\section{Observaciones al Texto:}

- $\quad$ En general, se puede apreciar que el capítulo de la Guerra con Chile está plagado de adjetivos despectivos y subjetivos, que lo único que crean en el estudiante es una conciencia antichilena. ${ }^{17}$

- Además se incentiva una conciencia de pérdida, de dolor, de víctima en el peruano, que es sumamente delicada en la formación del ciudadano, quien no desarrolla un sentido crítico para entender la derrota militar. ${ }^{18}$

\footnotetext{
${ }^{16}$ HOY Semanario chileno... Artículo de Nicolás Cruz Barros: En el Perú "los tiranuelos han suprimido la libre opinión, han creado un entusiasmo ficticio i luego de meterse en una guerra que no han sabido dirigir, han entregado al pueblo a una oprobiosa derrota. Preguntad por todas partes, "¿quién ha combatido en el Perú?" No ha habido allí pueblo heroico, actor como en nuestro caso. Hubo excesos, pues claro que los hubo en nuestro caso, pero éstos formaron parte de una realidad superior, fueron la cara débil de una de nuestras mayores virtudes."

17 Por eso llama la atención la afirmación de Teresa Chávez: "Los dos historiadores del siglo XX preocupados por la enseñanza secundaria, Jorge Guillermo Leguía y Gustavo Pons Muzzo, han marcado huella en la historiografía escolar peruana. Cada uno en su época, ambos trataron de entregar en sus textos escolares, elementos formativos para incentivar la identidad nacional." En: La enseñanza de la historia del Perú en la educación secundaria durante la segunda mitad del siglo XX. PUCP, 2006, p. 20.

18 "Los textos escolares se caracterizan por fomentar la memorización y el parafraseo de información puntual y no les proporciona a los alumnos oportunidades para establecer relaciones entre los datos
} 


\section{Reflexión Final:}

A pesar que en el Perú se han realizado diversas investigaciones y publicaciones sobre la Guerra de 1879, a nivel de textos escolares no se han recogido estos avances y se sigue transmitiendo un tipo de historia poco objetiva. Se desconoce el aporte del campesinado indígena, bajo el mando del caudillo Andrés Avelino Cáceres, quien los convoca y resiste, por razones económicas. Tampoco se habla de la tradición guerrera de los huancas, por ejemplo. Hay un divorcio entre la producción de los estudios históricos y los textos escolares.

Uno de los aspectos más importantes de este acontecimiento fue la injerencia británica, que poco o nada es mencionada en los textos escolares. “...en los meses en que comenzó la guerra... el Secretario de Estado de Estados Unidos, James Blaine, basándose en las informaciones a las que tenía acceso, declaró ante el Comité de Relaciones Exteriores del Congreso Norteamericano que la Guerra del Pacífico era una guerra inglesa contra el Perú con Chile como instrumento."19

Parte de la clase dirigente chilena era socia de algunas empresas y de capitalistas británicos que operaban en el Pacífico Sur, teniendo así intereses económicos comunes. En ese período los recursos económicos del territorio peruano de Tarapacá y del boliviano de Antofagasta eran enormes, así como también eran enormes los intereses compartidos de los chilenos y británicos que operaban en esas áreas.

"En la Guerra del Pacífico la defensa de la Doctrina del Libre Cambio, hecha por Chile y Gran Bretaña, convirtió a esos países en aliados -tenían intereses comunes - contra (o mejor dicho frente) al Perú que había optado por la vía opuesta -casi inédita- en América Latina, la de la Estatización (Monopolio Estatal del Salitre), como el instrumento esencial para reorganizar su economía."20 El Perú, en 1876, decretó la moratoria de su deuda externa (no olvidemos que los bonos de la deuda del Perú, estaban en manos británicas) ya que no tenía otra opción, acelerando así las tendencias estatizantes y nacionalistas, desde un gobierno liberal.

El conflicto bélico entre Chile y Perú liquidó sueños grandiosos, proyectos progresistas; al mismo tiempo fortaleció el control del capitalismo inglés. (Recordemos el proyecto liberal de 1872 con sus antecedentes en la Revista de Lima de 1859 a 1861). Así, esa guerra resulta ser un

presentes en el libro y sus propios conocimientos y experiencias. Los libros de texto no propician el desarrollo del pensamiento crítico." En: Thorne, Cecilia, Diana Cordano y Sheyla Blumen. Los textos escolares de primaria en el Perú, Lima, PUCP, Cisepa, 1993.

${ }^{19}$ Amayo, Enrique La Política Británica en la Guerra del Pacífico Lima, Editorial Horizonte, 1988.

${ }^{20}$ Amayo... Ibidem. 
capítulo importante de la génesis y expansión del capital mundial bajo hegemonía británica. Por eso, sería de gran importancia comprender el porqué de este conflicto, ubicándolo dentro del contexto mundial de su época, relacionándolo con la política que Gran Bretaña aplicaba a nivel internacional a partir de la instauración del libre comercio, usando cualquier medio para eliminar las barreras que se le opusieran.

Con este ingreso al tema, los textos escolares transmitirían menos encono entre los países vecinos como Chile y Perú y harían más viable el camino hacia la integración. A pesar de que el modelo de Integración está basado en intereses de capitales y del mercado, tiene un lado cultural, que consiste en fomentar la Integración en los términos de Bolívar, soñar la Patria Grande, para así poder enfrentarnos como un bloque de sociedades con un pasado común, ya que aisladamente no podemos negociar con otros bloques como el Mercado Común Europeo o el Tratado Estados Unidos, Canadá y México. Tal vez podamos retomar el sueño de Bolívar en el sentido más práctico, es decir, enseñando la historia más objetiva, menos militar, para autoafirmarnos como la Patria Grande.

Quisiera terminar citando al maestro Jorge Basadre, historiador de la República y nacido en Tacna en 1903, como un ejemplo a tener muy presente para reescribir la historia de los textos escolares sin adjetivaciones pero con firmeza y con la verdad.

"En septiembre de 1880 , una expedición chilena a cargo de Patricio Lynch recorrió la costa norte del Perú, imponiendo cupos en dinero y en especies, inutilizando los ferrocarriles y destruyendo las propiedades de los dueños peruanos que no accedían a sus reclamos. Esta expedición, formada por casi dos mil hombres, desembarcó en distintos puertos norteños sembrando la destrucción."21

"El impacto de la guerra había sido terrible. No sólo los estragos de los muertos y heridos, la ruina en los campos de batalla, las humillaciones de la ocupación, el empobrecimiento a todo ello inherente, más el que provenía de la perdida de Tarapacá. Había algo aún peor: la desesperación de la derrota, las agrias acusaciones de peruanos contra peruanos, la ira que en muchos se había convertido en abatimiento, la postración espiritual."22

\footnotetext{
${ }^{21}$ Basadre, Jorge. Historia de la República del Perú. Tomo VIII.

22 Basadre, Jorge. Sultanismo, Corrupción y Dependencia en el Perú Republicano. Lima, Editorial Milla Batres, 1979.
} 


\section{REFERENCIAS BIBLIOGRÁFICAS}

AMAYO, Enrique. La Política Británica en la Guerra del Pacífico. Lima: Editorial Horizonte, 1988.

BASADRE, Jorge. Historia de la República el Perú - Tomo VIII. Lima: Editorial Universitaria, 1983.

BASADRE, Jorge. Sultanismo, Corrupción y Dependencia en el Perú Republicano. Lima: Editorial Milla Batres, 1979.

BOLÍVAR, Simón. Doctrina del Libertador. Caracas: Editorial Biblioteca Ayacucho, 1979.

BULNES, Gonzalo. Guerra del Pacífico. Santiago de Chile: Editorial Talleres Gráficos Corporación Ltda., 1979.

CASTILLO MORALES, Juan. Historia del Perú en el Proceso Americano y Mundial 4, Lima: Editorial Bruño.

CHÁVEZ, Teresa. La enseñanza de la historia del Perú en la educación secundaria durante la segunda mitad del siglo XX. Lima: Editorial Pontificia Universidad Católica del Perú, 2006. Ciencias Sociales 4 - Secundaria, Editorial Santillana S.A., Lima, 2008.

DÍAZ CASTAÑEDA, Jaime y OSPINA ORTIZ, Jaime. La Enseñanza de la Historia como Estrategia de Integración. Bogotá: Editorial SECAB-Codecal, 1995.

EGUREN, Mariana, DE BELAUNDE, Carolina y GONZÁLEZ, Natalia. Recursos Desarticulados El uso de textos en la escuela pública. Lima: Editorial Instituto de Estudios Peruanos, 2005.

MACERA, Pablo. Visión Histórica del Perú. Lima: Editorial Milla Batres, 1978.

PONS MUZZO, Gustavo. Compendio de Historia del Perú. Lima: Editorial Bruño, 1995. Revista Hoy - 100 años después La Guerra del Pacífico. Santiago de Chile: Editorial Araucaria Ltda., 1979.

THORNE, Cecilia, CORDANO Diana y BLUMEN, Sheyla. Los textos escolares de primaria en el Perú. Lima: Editorial Cisepa de la Pontificia Universidad Católica del Perú, 1993.

Cecilia Israel La Rosa. Historiadora de la Pontificia Universidad Católica del Perú, tiene un doctorado en la Universidad de Ciencias Sociales de Grenoble, Francia. Se ha desempeñado como profesora de los Talleres de Investigación del Centro de Investigación de la Universidad del Pacífico. Coautora de los libros: Lima Años Treinta. Salarios y Costo de Vida de la Clase Trabajadora y Obreros Frente a la Crisis. Testimonios de los Años Treinta. Ha publicado artículos sobre Los Liberales del Siglo XIX en la Revista Banca y en Humanitas de la Universidad de Lima. También ha dado a la imprenta Crisis, Partidos y 
Sindicatos de la Lima de los Treinta en Historia del Movimiento Obrero, Editora Nacional, Quito. Ha sido relatora del Grupo de Trabajo: Enseñanza de la Historia y Cultura de Paz, Seminario organizado por la Asociación Peruana de Estudios e Investigación para la Paz y UNESCO. Desde el 2001 es coordinadora del Programa Internacional de Becas de Postgrado financiado por la Fundación Ford y ejecutado por el Instituto de Estudios Peruanos.

cisrael@iep.org.pe

Recepción: 10 de noviembre 2008. Aprobación: 20 de diciembre 2008. 